\title{
Tolerance of intragastric balloon and patient's satisfaction in obesity treatment
}

\author{
Kryspin Mitura, Karolina Garnysz \\ Department of General Surgery, Siedlce Hospital, Siedlce, Poland
}

Videosurgery Miniinv 2015; 10 (3): 445-449

DOI: 10.5114/wiitm.2015.54047

\begin{abstract}
Introduction: The dietary management of obesity is associated with a high failure rate. Methods which enable the long-term reduction of food intake have been developed. Patients treated with an intragastric balloon may experience some unwanted symptoms during therapy. The severity of these symptoms may result in poor tolerance of treatment, while patients who do not experience these symptoms may refuse to follow dietary modifications. In these cases, weight reduction at the end of treatment may be below expectations.

Aim: To assess the tolerance of intragastric balloon treatment in obese patients as well as their satisfaction with this treatment.

Material and methods: Fifty-seven gastric balloon procedures were performed in 51 females and 6 males aged 17 to 65 years (39.5 \pm 10.7 years). Baseline weight was $104 \pm 14.5 \mathrm{~kg}(78-140 \mathrm{~kg})$, body mass index $37.2 \pm 4.1 \mathrm{~kg} / \mathrm{m}^{2}$ $\left(29.8-48.1 \mathrm{~kg} / \mathrm{m}^{2}\right)$, mean excess body weight $41.2 \pm 11.5 \mathrm{~kg}(20.4-63.1 \mathrm{~kg})$. The balloon was filled with $669 \pm 25.8 \mathrm{ml}$ of saline solution $(550-700 \mathrm{ml})$. Upon balloon removal 6 months later, the patients completed a 12-question survey. Results: We obtained 57 surveys. The most common symptoms included vomiting, heartburn, abdominal pain and others. Twenty-two patients reported $>2$ symptoms. Two patients were symptom-free. The mean duration of symptoms was 24.8 days. Patients reported better control of hypertension, diabetes and resolution of obstructive sleep apnoea and joint symptoms. Only 14 patients did not observe any significant improvement in their bodily function. Fifty-four patients expressed satisfaction after treatment, 6 patients were dissatisfied with the weight loss, and 5 patients would not opt for balloon re-treatment.
\end{abstract}

Conclusions: The balloon treatment is a safe and well-tolerated therapy with a low complication rate.

Key words: obesity, intragastric balloon, satisfaction, tolerance.

\section{Introduction}

Obesity management aims at a sustained, continuous total weight loss (TWL) by 5-10\% [1]. Effective treatment of obesity must be based on a correct energy balance, which means a reduced caloric intake for most patients. Unfortunately, the dietary management of obesity is associated with a failure rate of $80-90 \%$ [2-4]. That is why methods have been developed which enable the long-term reduc- tion of food intake. Patients who refuse or are not eligible for restrictive bariatric procedures can be treated with an intragastric balloon. It is also recommended as a part of preparation for elective bariatric surgery in order to minimise perioperative complications [5]. As the balloon is rapidly filled with fluid, it induces the sensation of a full stomach, which may cause some unwanted symptoms. The most common of them are nausea and vomiting, whose duration differs in different individuals. The severi-

\section{Address for correspondence}

Kryspin Mitura MD, PhD, Department of General Surgery, Siedlce Hospital, 15 Starowiejska St, 08-110 Siedlce, Poland,

phone: +48 602809 035, e-mail: chirurgia.siedlce@gmail.com 
ty of these symptoms may result in poor tolerance and refusal of intragastric balloon treatment. At the same time, patients who do not experience these symptoms, or in whom the symptoms are mild, may refuse to follow dietary modifications. In these cases, body weight reduction at the end of treatment may be below the expected level.

\section{Aim}

The aim of this study was to assess the tolerance of intragastric balloon treatment in obese patients as well as their satisfaction with this treatment.

\section{Material and methods}

Between January and October 2012, we performed 57 gastric balloon procedures in obese patients. Informed consent was obtained from all individual participants included in the study. The cohort included 51 females and 6 males at the age of 17 to 65 years (mean age: $39.5 \pm 10.7$ years). At baseline, the mean total body weight in our group was 104 $\pm 14.5 \mathrm{~kg}$ (range: $78-140 \mathrm{~kg}$ ), the mean body mass index was $37.2 \pm 4.1 \mathrm{~kg} / \mathrm{m}^{2}$ (range: $29.8-48.1 \mathrm{~kg} / \mathrm{m}^{2}$ ), and the mean excess body weight calculated using the formula proposed by the American Society of Metabolic and Bariatric Surgery was $41.2 \pm 11.5 \mathrm{~kg}$ (range: 20.4-63.1 kg) [6]. Eleven subjects in our cohort were diagnosed with diabetes and 30 reported hypertension. All intragastric balloon insertion procedures were performed under general anaesthesia by the same endoscopic surgeon. The Orbera Intragastric Balloon (Allergan, Santa Barbara, California, USA) was filled with saline solution with a mean volume of $669 \pm 25.8 \mathrm{ml}$ (range: $550-700 \mathrm{ml}$ ). The saline volume depended on the subjective gastric volume assessment following endoscopic insufflation as well as patient body height. The patients were discharged on day 1 following the procedure. The discharge recommendations included the use of a proton pump inhibitor (omeprazole) for at least 1 week or until reflux symptoms resolution, as well as a gastroprokinetic agent (cisapride). The patients were advised to follow a semi-liquid diet for the first week consisting of frequent, low-volume meals. In the subsequent period, the patients were instructed by the dietician to follow a $1100 \mathrm{kcal}$ diet and to increase their physical activity. The intragastric balloon was removed at 6 months during the endoscopic procedure performed under general anaesthesia.
Upon balloon removal, the patients were requested to complete the 12-question survey to assess their satisfaction with treatment.

\section{Statistical analysis}

The statistical analysis of the basic data performed using Excel 2010 (Microsoft) enabled identification of mean values and standard deviation $( \pm)$. The $t$-test was used for comparisons and values below 0.05 were considered statistically significant.

\section{Results}

One female subject needed to have the intragastric balloon removed due to poor treatment tolerance (persistent vomiting, signs of dehydration and electrolyte imbalance) 2 weeks after the primary insertion procedure. Upon balloon removal 6 months later, the mean BMI in our study group $(n=57)$ was $31.5 \pm 4.0 \mathrm{~kg} / \mathrm{m}^{2}$ ( $p<0.001$ ), the mean total body weight was $87.6 \pm 15.0 \mathrm{~kg}(p<0.001)$ and the mean body weight loss was $15.9 \mathrm{~kg}$, which can be translated into $41 \pm 19.6 \%$ of the excess weight loss (EWL) ( $p<0.001)$. Only one patient was classified as a non-respondent. Satisfactory results, that is the reduction of $>10 \% \mathrm{TWL}$, were achieved in all other patients. The mean BMI reduction was $5.8 \mathrm{~kg} / \mathrm{m}^{2}$ $(15.5 \%)$ and it was statistically significant $(p<0.001)$.

We obtained 57 properly completed surveys, which were analysed. The most common unwanted symptoms reported by our subjects included vomiting in 33 (57.9\%) patients and heartburn in 27 (47.4\%) patients. Thirteen $(22.8 \%)$ patients reported abdominal pain and 11 (19.3\%) patients reported other unwanted symptoms. Only 3 patients admitted that they found following the dietary regimen the most difficult part of their treatment. Twenty-two (38.6\%) patients reported more than two unwanted symptoms, whereas only 5 subjects reported three or more symptoms. Only 2 patients did not report any symptoms. Individuals who reported at least two unwanted symptoms achieved the highest BMI reduction as compared to other patients $-6.2 \mathrm{~kg} / \mathrm{m}^{2}$ vs. $5.4 \mathrm{~kg} / \mathrm{m}^{2}(p=0.114)$. The mean duration of these symptoms was 24.8 days. They resolved within a week in 33 (57.9\%) patients and persisted throughout the entire treatment in 3 (5.3\%) cases. Excluding these two extremes, the mean duration of unwanted symptoms in the remaining patients was $34.1 \pm 25.4$ days. In the subgroup of subjects who reported the 
unwanted symptoms persisting for over 7 days, the mean $\mathrm{BMI}$ reduction was $5.65 \mathrm{~kg} / \mathrm{m}^{2}$, compared to $5.93 \mathrm{~kg} / \mathrm{m}^{2}$ in the remaining patients $(p=0.336)$.

All patients were referred to the dietician after the intragastric balloon insertion. However, only 10 of them (17.5\%) actually used this support during treatment. They were also instructed to abstain from simple carbohydrate intake during treatment. Twenty-six (45.6\%) patients confirmed they followed that instruction. Treatment outcomes were more favourable in these patients, as compared to sweet eaters, both in terms of TWL and BMI reduction, which were $17.8 \pm 4.8 \mathrm{~kg}$ vs. $15.2 \pm 6.9 \mathrm{~kg}$ and $6.4 \pm 2.0 \mathrm{~kg} / \mathrm{m}^{2}$ vs. $5.3 \pm 2.7 \mathrm{~kg} / \mathrm{m}^{2}(p=0.047)$, respectively.

During the follow-up visit, 12 (21.0\%) patients reported better control of hypertension, 8 (14.0\%) patients reported better control of their diabetes and $7(12.3 \%)$ patients reported resolution of their obstructive sleep apnoea. The majority of patients reported improvement in bone and joint symptoms, which involved their spine in $24(42.1 \%)$ cases, knees in 18 (31.6\%) cases and hips in 11 (19.3\%) cases. Only 14 patients did not observe any significant improvement in their bodily function. The mean TWL and the mean BMI reduction in this group were $13.4 \mathrm{~kg}$ and $4.8 \mathrm{~kg} / \mathrm{m}^{2}$, respectively. The mean TWL and the mean BMI reduction in a subgroup of patients reporting an improvement regarding a single symptom were $15.6 \mathrm{~kg}$ and $4.9 \mathrm{~kg} / \mathrm{m}^{2}$, respectively. The same values were $17.3 \mathrm{~kg}$ and $6.6 \mathrm{~kg} / \mathrm{m}^{2}$ as well as $20.6 \mathrm{~kg}$ and $7.4 \mathrm{~kg} / \mathrm{m}^{2}(p=0.01)$ in the subgroups reporting an improvement regarding 2 and 3 or more symptoms, respectively.

The vast majority of patients expressed their overall satisfaction with the intragastric balloon treatment. Only 3 (5.3\%) patients expressed their lack of satisfaction with this treatment. At the end of treatment, 6 (10.5\%) patients expressed their dissatisfaction with body weight loss (mean BMI reduction by $3.2 \mathrm{~kg} / \mathrm{m}^{2}$, TWL by $8.5 \mathrm{~kg}$ ). At the same time, only 5 patients would not opt for intragastric balloon re-treatment. This subgroup involved 2 patients who reported the unwanted symptoms throughout the entire treatment duration and 2 individuals whose total body weight loss was lower than $8 \mathrm{~kg}$. Only 1 patient would not recommend this treatment to others.

\section{Discussion}

Many authors consider vomiting to be inseparably associated with intragastric balloon treatment, especially at the early stages of treatment. Its onset is within a few hours following the procedure and it persists for a few days $[7,8]$. The stomach adapts to the intragastric device within a few days. As a result, spontaneous vomiting resolves and what remains is vomiting associated with faulty dietary practice, such as the intake of excessive food or fluid volume. Vomiting is an unpleasant symptom which limits patients' ability to perform their social roles. If it persists for a long time, the patients may become dissatisfied with treatment and discouraged to opt for it in the future. Intensive vomiting may lead to dehydration and hypokalaemia in rare cases. This constitutes an indication for intragastric balloon removal when an attempt to restore fluid balance by intravenous infusion fails. We had $1(1.3 \%)$ case like that, in which the intragastric balloon was removed 2 weeks after the primary insertion. However, according to other authors this may be necessary in $6.7-13.6 \%$ of patients [9-11].

Having reviewed 16 studies on a total of 1402 patients treated with an intragastric balloon, the research team from Amsterdam found that early and late vomiting occurs in $35.2 \%$ and $9.9 \%$ of patients, respectively; early and late reflux occurs in $3.7 \%$ and $4.4 \%$ of patients, respectively; and early/late abdominal discomfort is reported by $11.6 \%$ and $5.8 \%$ of patients, respectively [11]. In our cohort, these symptoms were reported more frequently. Like other researchers, we observed their gradual resolution in most patients.

In order to improve treatment outcomes, the second generation of air-filled intragastric balloons is being used nowadays. Against prior expectations, the tolerance of both methods as well as treatment outcomes are similar [12]. Furthermore, the use of fluid-filled balloons carries lower risk of spontaneous deflation, which might lead to severe complications including life-threatening bowel obstruction or perforation. We filled the intragastric balloons with saline solution and did not observe any leakage. The fluid volume used for filling the balloon was recorded for each subject and compared with the amount of fluid evacuated from the balloon upon its removal. We achieved full compliance in all cases, thus confirming that the intragastric balloons were watertight. In order to avoid damage to the intragastric balloon, the removal procedure was scheduled for 6 months following the insertion. We observed areas of erosion on the smooth silicone surface of 
intragastric balloons removed from some patients, which supports the progressive damage to the balloon structure. Likewise, these balloons tended to rupture easily upon removal using the wire grasper. Hence, it can be hypothesized that the prolonged presence of an intragastric balloon in the stomach may lead to additional complications, so the manufacturer-recommended treatment timeframe should not be exceeded. Some authors point to the fact that treatment outcomes depend on the fluid volume used for filling the intragastric balloon [8]. Each time, the amount of fluid was administered so as to fill the balloon up to the maximum, which was evaluated subjectively. In order to assess it, endoscope retroflexion was performed in the distal end of the stomach at the end of the procedure and rugae of mucosa were evaluated - the balloon was considered fully filled when it visibly touched the stomach wall during insufflation and the rugae adjacent to it appeared flat. There was a correlation between the balloon volume and patient body height. That is why expecting better treatment outcomes just with increasing the balloon volume appears unreasonable. In line with the assumptions discussed above, the amount of fluid used for filling the intragastric balloon should not exceed the amount we administered. Otherwise, it might induce balloon intolerance and additional complications due to gastric mucosal damage (erosion, ulcer, perforation), as reported by other authors, which we did not observe in our cohort [13]. The oral administration of a proton pump inhibitor to all patients might have had some protective effect in this respect.

The balloon volume cannot be the same for all patients, as confirmed by Geliebter, who observed decreasing body weight loss with the increasing stomach volume, at a constant volume of the intragastric balloon [14]. It should be emphasized that the major body weight loss takes place within the first 3 months of treatment $[9,15]$. Most unwanted treatment-related symptoms resolve in the same time frame. In our cohort, only 3 (4\%) patients reported unwanted symptoms persisting for over 90 days. Doldi noted improved glycaemic control in patients after intragastric balloon-induced body weight loss [16]. Our patients also reported better control of their diabetes and hypertension. It was one of the factors contributing to their overall high satisfaction with treatment, apart from the improved general disposition and body image. A small percent- age of our subjects claimed they would not opt for intragastric balloon re-treatment, mostly due to unwanted symptoms persisting over the entire treatment duration, as well as unfulfilled expectations regarding their body weight reduction. Regardless of that, they would all (except for one female subject) recommend this treatment to other patients. Some authors support the routine referral to the dietician during treatment $[8,9]$. However, we did not observe any correlation between dietician support and treatment outcomes in our study sample. The only statistically significant difference regarded the patient-led reduction of simple carbohydrate intake, which improved treatment outcomes. Nevertheless, it appears reasonable to provide the dietician support to patients after the intragastric balloon removal, when the mechanical stomach filling effect has resolved and they have to rely on newly developed dietary habits. This is of particular importance, since as many as half of them are at risk of a rapid body weight increase $[16,17]$.

\section{Conclusions}

The balloon treatment is a safe and well-tolerated therapy with a low complication rate. Outcomes are more favourable in patients who abstain from glucose intake.

\section{Conflict of interest}

The authors declare that they have no conflict of interest.

\section{References}

1. WHO. Obesity: preventing and managing the global epidemic. Report of a WHO consultation. WHO Technical Report Series 894, vol. 894. WHO, Geneva 2000; 1-253.

2. Dalle Grave R, Calugi S, Molinari E, et al. QUOVADIS Study Group. Weight loss expectations in obese patients and treatment attrition: an observational multicenter study. Obes Res 2005; 13: 1961-9.

3. Moroshko I, Brennan L, O'Brien P. Predictors of dropout in weight loss interventions: a systematic review of the literature. Obes Rev 2011; 12: 912-34.

4. Vanderlinden J, Adriaensen A, Vancampfort D, et al. A cognitive-behavioral therapeutic program for patients with obesity and binge eating disorder: short- and long-term follow-up data of a prospective study. Behav Modif 2012; 36: 670-86.

5. Busetto L, Segato G, De Luca M, et al. Preoperative weight loss by intragastric balloon in super-obese patients treated with laparoscopic gastric banding: a case control study. Obes Surg 2004; 14: 671-6. 
6. Oria HE, Carrasquilla C, Cunningham P, et al. Guidelines for weight calculations and follow-up in bariatric surgery. Surg Obes Relat Dis 2005; 1: 67-8.

7. Astrup A, Rossner S. Lessons from obesity management programmes: greater initial weight loss improves long-term maintenance. Obes Rev 2000; 1: 1-9.

8. Roman S, Napoleon B, Mion F, et al. Intragastric balloon for "non-morbid" obesity: a retrospective evaluation of tolerance and efficacy. Obes Surg 2004; 14: 539-44.

9. Abdulhameed AM, Ibrahim EM. Intragastic balloon for balloon for obesity: a retrospective evaluation of tolerance and efficacy. Obes Surg 2005; 15: 101-5.

10. Ohta M, Kitano S, Kai S, et al. Initial Japanese experience with intragastric balloon placement. Obes Surg 2009; 19: 791-5.

11. Mathus-Vliegen E. Intragastric balloon treatment for obesity: what does it really offer? Dig Dis 2008; 26: 40-4.

12. De Castro ML, Morales MJ, Del Campo V, et al. Efficacy, safety, and tolerance of two types of intragastric balloons placed in obese subjects: a double-blind comparative study. Obes Surg 2010; 20: 1642-6.

13. Drozdowski R, Wyleżoł M, Frączek $M$, et al. Small bowel necrosis as a consequence of spontaneous deflation and migration of an air-filled intragastric balloon - a potentially life-threatening complication. Videosurgery Miniinv 2014; 9: 292-6.

14. Geliebter A, Melton PM, McCray RS, et al. Clinical trial of silicone-rubber gastric balloon to treat obesity. In J Obes 1991; 15: 259-66.

15. Kotzampassi K, Grosomanidis V, Papakostas P, et al. 500 Intragastric balloons: what happens 5 years thereafter? Obes Surg 2012; 22: 896-903.

16. Doldi SB, Micheletto G, Perrini MN, et al. Treatment of morbid obesity with intragastric balloon in association with diet. Obes Surg 2002; 12: 583-7.

17. Angrisani L, Lorenzo M, Borrelli V, et al. Is bariatric surgery necessary after intragastric balloon treatment? Obes Surg 2006; 16: 1135-7.

Received: 6.06.2015, accepted: 22.07.2015. 